\title{
Spatial and temporal attention in developmental dyslexia
}

\author{
Milena Ruffino ${ }^{1 *}$, Simone Gori ${ }^{1,2}$, Daniela Boccardi ${ }^{2}$, Massimo Molteni ${ }^{1}$ and Andrea Facoetti ${ }^{1,2}$ \\ Child Psychopathology Unit, Scientific Institute, IRCCS Eugenio Medea, Lecco, Italy \\ ${ }^{2}$ Developmental and Cognitive Neuroscience Lab, Department of General Psychology, University of Padua, Padua, Italy
}

\section{Edited by:}

Alan James Power, University of

Cambridge, UK

Reviewed by:

Nicholas Allan Badcock, Macquarie

University, Australia

Manon Wyn Jones, Bangor

University, UK

${ }^{*}$ Correspondence:

Milena Ruffino, Child

Psychopathology Unit, Scientific

Institute, IRCCS Eugenio Medea,

Via Don Luigi Monza, 20,

Bosisio Parini, Lecco 23842, Italy

e-mail:milena.ruffino@bp.Inf.it
Although the dominant view posits that developmental dyslexia (DD) arises from a deficit in phonological processing, emerging evidence suggest that DD could result from a more basic cross-modal letter-to-speech sound integration deficit. Letters have to be precisely selected from irrelevant and cluttering letters by rapid orienting of visual attention before the correct letter-to-speech sound integration applies. In the present study the time-course of spatial attention was investigated measuring target detection reaction times (RTs) in a cuing paradigm, while temporal attention was investigated by assessing impaired identification of the first of two sequentially presented masked visual objects. Spatial and temporal attention were slower in dyslexic children with a deficit in pseudoword reading $(N=14)$ compared to chronological age $(N=43)$ and to dyslexics without a deficit in pseudoword reading $(N=18)$, suggesting a direct link between visual attention efficiency and phonological decoding skills. Individual differences in these visual attention mechanisms were specifically related to pseudoword reading accuracy in dyslexics. The role of spatial and temporal attention in the graphemic parsing process might be related to a basic oscillatory "temporal sampling" dysfunction.

Keywords: spatial attention, temporal attention, temporal sampling, phonological decoding, reading disorder

\section{INTRODUCTION}

Developmental dyslexia (DD) is a neurodevelopmental disorder identified in about $10 \%$ of children which refers to a pattern of learning difficulties characterized by problems with accurate or fluent word recognition, poor decoding and poor spelling abilities, despite normal intelligence, and adequate access to conventional instruction (American Psychiatric Association, 2013).

According to the dual-route model (see Perry et al., 2007 for a review), written words can be processed either by the sub-lexical route, based on grapheme-to-phoneme correspondences, allowing us to read unfamiliar words and pseudowords, or by the lexical route, based on lexical unit correspondences, crucial for reading familiar and irregular words only. Phonological dyslexics show great difficulties in reading unfamiliar words and pseudowords compared to known words, and this is thought to arise from damage to the sub-lexical route. In contrast, surface dyslexia is characterized by impaired reading of irregular words, and this is thought to arise from a damage in the lexical route (e.g., Castles and Coltheart, 1993), potentially linked to an under-stimulation of the visual word recognition system resulting from low experience with literacy. However, in shallow orthographies such as Italian, spelling-sound irregularity is limited to the supra-segmental level (that is, to stress assignment). Thus, in Italian dyslexic children the increased weighting of sub-lexical processing does not permit precise measurement of the efficiency of the lexical-route (see also Gori et al., under revision). It is crucial to note thatregardless of spelling-sound regularity—-for a beginning reader all words are at first pseudowords because the lexical-orthographic representations have still to be developed. Accordingly, most longitudinal studies have shown that beginning readers use primarily the sub-lexical route (see Sprenger-Charolles et al., 2003, for a review). Phonological decoding, which is typically measured by examining children's pseudoword reading performance, is one of the most critical skills for successful reading acquisition (e.g., Share, 1995). Interestingly, Ziegler et al. (2003) showed that dyslexics with both regular (German-speaking children) and irregular (English-speaking children) spelling-to-sound correspondences present an extremely slow and serial phonological decoding mechanism. Consequently, an efficient learning to read is crucially mediated by an accurate and fluent use of the sublexical route (e.g., Goswami et al., 2000; see Vellutino et al., 2004, for a review).

The underlying neurocognitive mechanisms that lead to the observed reading impairments are still hotly debated (see Vidyasagar and Pammer, 2010; Goswami, 2011). Impaired auditory and speech-sound processing is assumed to characterize the core deficit in DD (e.g., Tallal, 1980; Bradley and Bryant, 1983; Chandrasekaran et al., 2009; Vandermosten et al., 2010; Hornickel et al., 2012; see Wright et al., 2000; Goswami, 2003, 2011; Tallal, 2004; Gabrieli, 2009; Peterson and Pennington, 2012, for reviews). However, the hypothesis that DD arises specifically from a deficit of phonological awareness is still debated because of the circular relationship between reading ability and phonological skills acquisition (e.g., Blau et al., 2009; Dehaene et al., 2010; see Castles and Coltheart, 2004, for a review).

Emerging evidence suggested that DD could arise from a more basic cross-modal letter-to-speech sound integration deficit (e.g., Blau et al., 2009, 2010; Dehaene et al., 2010; see Blomert, 2011, for a recent review). A recent study has also shown that cross-modal binding is impaired at the very early stages of associative learning (Jones et al., 2013). Those authors suggested that dyslexic readers' difficulties in binding may be characterized by 
inadequate attentional deployment to spatial location. Letters have to be precisely selected from irrelevant and cluttering letters (Bouma, 1970; Bouma and Legein, 1977) by rapid orienting of visual attention (Yeshurun and Rashal, 2010) before the correct letter-to-speech sound integration applies (e.g., Hari and Renvall, 2001; Facoetti et al., 2010a; Vidyasagar and Pammer, 2010; Zorzi et al., 2012). Accordingly, recent studies have shown that visual attention is impaired not only in dyslexic children (e.g., Facoetti et al., 2010a; Lallier et al., 2010), but also in prereaders at familial risk for DD. These results indicate that visual attention disorders are present before reading acquisition (e.g., Plaza and Cohen, 2007; Facoetti et al., 2010b) and that they are predictors of future reading acquisition skills controlling not only for age, IQ, and phonological processing, but also for nonalphabetic, visual-to-phonological mapping (Franceschini et al., 2012). Moreover, recent findings have shown that attentional training - not involving phonological or orthographic learningby using action video games can improve reading abilities in children with DD (Franceschini et al., 2013). Visual attention can be oriented in space and time as a spotlight (i.e., attentional shifting; Posner, 1980; Yantis and Jonides, 1984; Jonides and Yantis, 1998). The spotlight of attention (i.e., attentional focus) can also be expanded or contracted in spatial extent to encompass large or small objects, respectively (e.g., Castiello and Umiltà, 1990; LaBerge, 1995; Ronconi et al., 2014). When attention is spatially concentrated in a small portion of the visual field it is called focused attention, while when it is spread across a large part of the visual field it is called distributed attention.

A specific relationship between non-linguistic deficits referred to as attentional shifting has been proposed by Hari and Renvall (2001). According to their multisensory "Sluggish Attentional Shifting" (SAS) framework, when dyslexics deal with rapid stimulus sequences, their automatic attention system cannot disengage fast enough from one item to the next one, yielding slow and degraded processing. SAS is assumed to distort cortical networks, more specifically those which support sub-lexical auditory-phonological (e.g., syllables and/or phonemes) and visual-orthographic (e.g., syllables and/or grapheme) representations. Attentional shifting and rapid processing deficits have been proposed as a more basic problem yielding to the phonological impairment observed in DD (e.g., Breznitz et al., 2013; see Farmer and Klein, 1995; Tallal, 2004, for reviews). This hypothesis is supported by a number of studies showing evidence for temporal processing of brief stimuli within both visual and auditory modalities in dyslexic populations (e.g., Hari and Kiesilä, 1996; Helenius et al., 1999; Hari et al., 1999, 2001; Renvall and Hari, 2002). Consequently, it has been suggested that non-linguistic deficits in dyslexics can be linked to a generally inefficient multi-sensory processing of perceptual stimuli (e.g., perceptual noise exclusion deficit; Sperling et al., 2005; Ziegler et al., 2009; Facoetti et al., 2010a) that impairs the ability to detect relevant stimuli (i.e., signals) when encountering signal interference induced by spatially (Geiger and Lettvin, 1987; Sperling et al., 2005; Geiger et al., 2008; Ruffino et al., 2010) or temporally close noise (Di Lollo et al., 1983; Visser et al., 2004; Montgomery et al., 2005; Facoetti et al., 2008). Notably, attentional deficits in children with DD, with specific language impairment and with autism spectrum disorder (e.g., Ronconi et al., 2012, 2013a) arise from a difficulty in the visual noise exclusion process that specifically requires more time between two stimuli to identify accurately the target as compared to typically developing children (e.g., Ruffino et al., 2010; Dispaldro et al., 2013; Ronconi et al., 2013b).

It is important to highlight that spatial attention is involved in perceptual noise exclusion (e.g., Carrasco et al., 2000, 2002, 2004), by optimizing the perceptual filter so that the signal is further processed and noise is excluded (Dosher and Lu, 2000). The major effect on perceptual functions is that spatial attention appears to enhance the neural representation of stimuli at the attended location (see Reynolds and Chelazzi, 2004, for a review). This signal enhancement manifests itself in a variety of ways, including faster reaction times (RTs) (Posner, 1980), improved sensitivity (lowered thresholds; Carrasco et al., 2002) and reduced interference exerted by flanking stimuli (Carrasco et al., 2000; Facoetti and Molteni, 2000; Boyer and Ro, 2007). An important unresolved issue is whether spatial attention can also speed up the rate at which information is processed. Spatial attention not only improves the spatial resolution, but also accelerates the rate of information processing (Carrasco and McElree, 2001). Moreover, it allows decisions to be based on information at the selected location alone, while disregarding any distracting stimuli (Dosher and Lu, 2000; Braun, 2002). On the basis of these perceptual effects, spatial attention influences all post-sensorial processes, such as the content of short-term memory, perceptual decisions and voluntary responses.

SAS may be a crucial factor behind difficulties in learning to read (Hari and Renvall, 2001; Facoetti et al., 2005) and may be one important factor involved in perceptual difficulties, mostly in tasks requiring an efficient noise exclusion mechanism. Moreover, spatial attention deficits have been repeatedly shown in DD (e.g., Cestnick and Coltheart, 1999; Facoetti et al., 2005, 2006; Bosse et al., 2007; see Hari and Renvall, 2001; Vidyasagar and Pammer, 2010, for reviews) and more specifically in dyslexics with poor pseudoword reading ability (Cestnick and Coltheart, 1999; Buchholz and McKone, 2004; Facoetti et al., 2006, 2008; Roach and Hogben, 2007; Jones et al., 2008; Ruffino et al., 2010). The efficient learning of sub-lexical spelling-sound mappings requires not only accurate representations at the phoneme or syllabic level (Snowling, 2000; Goswami, 2003, respectively), but also an efficient graphemic parsing mechanism (Facoetti et al., 2006, 2010a; Perry et al., 2007; Ruffino et al., 2010; Vidyasagar and Pammer, 2010). These visual attentional processes are hypothesized to be crucially involved in spelling-to-sound conversion mechanisms. Computational models of silent or oral reading assume that graphemic parsing requires the serial engagement of visual attention onto, and its disengagement from, each sub-lexical unit. Among the processes necessary for adequate processing along the sub-lexical route, a graphemic parsing mechanism may be critically linked to the selection mechanism of visual attention (Zorzi, 2005; Perry et al., 2007; Zorzi et al., 2012; Schneps et al., 2013a,b).

Although it has already been demonstrated that visual spatial and temporal attention deficits could contribute independently to the poor reading outcome of dyslexic individuals, as yet, no studies have shown that both spatial and temporal attentional deficits co-occur in the same group of children with DD. These findings 
indicate that a sluggish shifting of spatial attention is specifically related to a perceptual noise exclusion deficit in DD.

Thus, in the current study, we investigated whether both spatial and temporal attention are impaired in DD with poor phonological decoding, and if they have a specific predictive relationship with phonological decoding skill.

We measured the time-course of visual spatial attention (VSA) and visual temporal attention (VTA) in two groups of dyslexic children, classified on the basis of their phonological decoding (dis)ability, and one group of controls matched for chronological age and IQ.

VSA has been extensively studied by using spatial cuing paradigms (Posner, 1980), in which covert attention (without eye movements) is engaged across two locations of a forthcoming target stimulus by a peripheral, informative spatial cue (i.e., cue location predicts target location) at two variable cue-target intervals (100 and $350 \mathrm{~ms}$ ). Stimuli presented at the valid location are detected faster than stimuli appearing at the invalid location (the cuing effect reflects facilitation and inhibitory mechanisms of attention; see Figure 1). These attentional effects have been interpreted as a consequence of enhanced sensory processing of stimuli appearing at attended locations (Posner, 1980; Carrasco et al., 2000, 2002, 2004), and indicate that VSA has been efficiently engaged. Processing facilitation in VSA is usually found at short cue-target delays only (e.g., 50-150 ms; see Klein, 2000, for a review; see also Facoetti et al., 2010a). Therefore, sluggish VSA might be revealed by a delay in the normal time-course of VSA, i.e., this attentional processing facilitation should be present at longer but not at shorter cue-target delays.

VTA was measured by using an identification task in which the first of two sequentially and centrally presented, forward and backward masked objects had to be recognized (i.e., signal + noise condition; Duncan et al., 1994), and it was compared to the

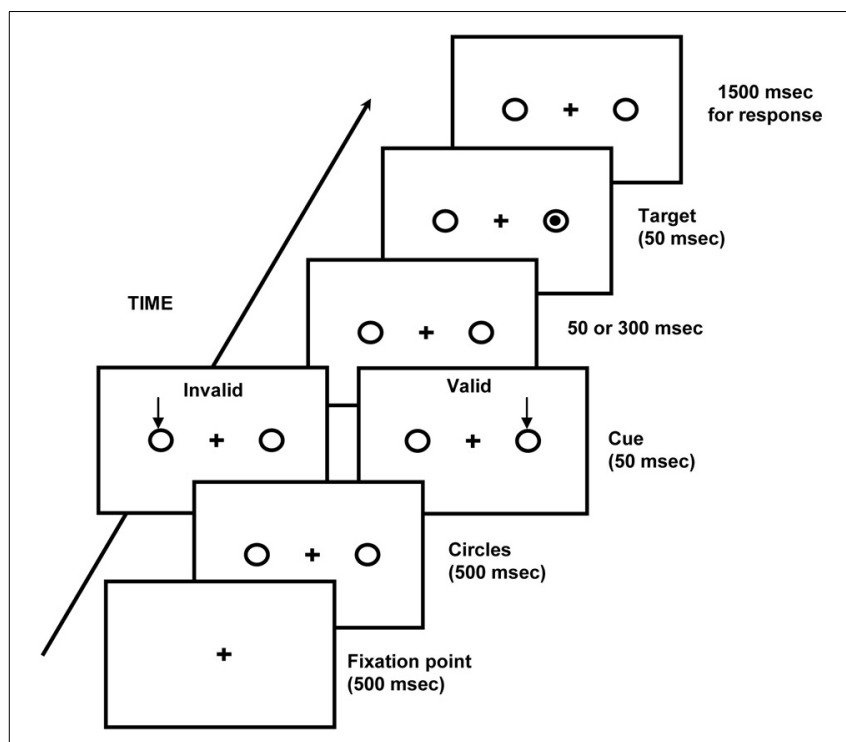

FIGURE 1 | Schematic representation of the display used in the visual spatial attention task. identification of a single displayed object (signal condition). The first visual object (O1) preceded the onset of the second visual object $(\mathrm{O} 2)$, by a short stimulus-onset-asynchrony (150 ms O1O2 SOA; Facoetti et al., 2008). However, in order to highlight the $\mathrm{O} 2$ perceptual segregation and simplify the task for children, it was displayed in a different color from O1 (see Figure 2A). The accuracy to identify $\mathrm{O} 1$ allowed us to measure the efficiency of temporal engagement onto a centrally presented visual object.

\section{MATERIALS AND METHODS PARTICIPANTS}

Participants were 32 Italian children with DD recruited at the Child Psychopathology Unit, Scientific Institute, IRCCS Eugenio Medea, Bosisio Parini, Lecco. Chronological age ranged from 8 to 14 (mean $=10, S D=1.85)$. Reading performance, in terms of accuracy and/or speed, was 2 SDs below the norm on at least one of the age-standardized Italian tests included in the clinical battery (single word and pseudoword reading; Sartori et al., 1995). Dyslexics were selected on the basis of: (i) a full scale IQ greater than 85 , as measured by the Wechsler Intelligence Scale for Children-Revised (WISC-R, Wechsler, 1993); (ii) normal or corrected-to-normal vision and hearing; (iii) the absence of neurological and/or psychiatric disorders; and (iv) the absence of attention deficit disorder with or without hyperactivity (because of its high co-morbidity with DD), as evaluated through DSMIV diagnostic criteria (American Psychiatric Association, 1994). None of the dyslexic children followed an intensive nor a specific training based on well-documented efficacy. Forty-three typically reading children (NR), matched on age and IQ, were also selected. They were aged between 7 and 14 years (mean $=10$, $S D=2.31)$ and were recommended as typical readers by their parents, confirmed by individual evaluation in a quiet room in their school. Reading performance was considered typical when accuracy and speed were higher than 1 SD below the norm of the age-standardized Italian tests included in the clinical battery

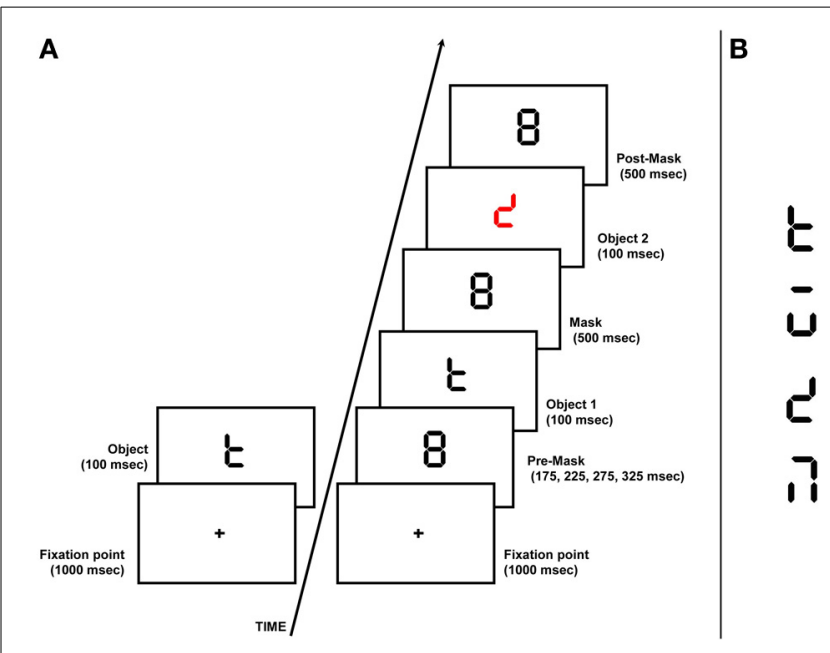

FIGURE 2 | Schematic representation of the display used in the visual temporal attention task (A); Stimuli used in the visual temporal attention task (B). 
(single word and pseudoword reading task; Sartori et al., 1995). Informed written consent was obtained from the parents of each child, and the Scientific Institute, IRCCS “Eugenio Medea” ethics committee approved the research protocol. The entire research process was conducted according to the principles expressed in the Declaration of Helsinki. Dyslexic and normally reading children were comparable for chronological age (two-tailed $t$ test, $p=0.96$ ) and Performance IQ (Figure Completion subtest, WISC-R, Wechsler, 1993; two-tailed $t$-test, $p=0.09$ ), but they were significantly different for both accuracy and speed of word and pseudoword reading (two-tailed $t$-test, all $p s<0.0001$ ).

\section{DYSLEXIA SUB TYPING}

In order to study the sub-lexical route efficiency, dyslexic children were divided into two groups on the basis of their accuracy in phonological decoding. In particular, their ability to read aloud was measured on a list of 50 Italian regular and 50 Italian irregular words and 50 pseudowords, in order to assess phonological decoding ability. We measured only accuracy in our study because low accuracy is frequently a problem observed even in Italian dyslexics (e.g., Facoetti et al., 2006, 2010a; Ruffino et al., 2010). Specifically, a dyslexic child was assigned to the DDP- group (where P- indicates severe pseudoword reading) if pseudoword reading accuracy was below the 5th percentile in comparison to normally reading children. We selected this criterion in order to find an inefficient sub-lexical route. All dyslexic children who did not meet the criterion for inclusion in the DDP- group were assigned to the DDP+ group (where $\mathrm{P}+$ indicates less severe pseudoword reading). The percentage mean of pseudoword reading accuracy was $64 \%(S D=10.14)$ for the $\mathrm{DDP}-$ and $79 \%$ $(S D=14.83)$ for the DDP + group $(p<0.0001)$.

\section{PHONOLOGICAL TASKS}

We administered a Pseudowords Phoneme Blending (PPB) task and a Pseudoword Short-Term Memory (PSTM) task to the participants.

In the PPB task, single phonemes were presented, and participants were asked to pronounce the resulting pseudowords from their synthesis (i.e., G-A-S-T-I-B-O = GASTIBO). Performances were calculated on the basis of the number of pseudowords correctly pronounced (the number of words administered were one for familiarization, nine experimental; the number of phonemes included in each pseudoword ranged from 7 to 10). The PSTM task consisted of repeating lists of pseudoword trigrams orally presented (i.e., two items ranging from 2 to 8 trigrams) in the same order as originally presented. Performances were indexed as the number of phonemes correctly repeated in the correct position (the maximum score was 210 phonemes). The number of list items increased with correct responses until participants made an error in both list items administered of the same length. For additional details see Supplementary Material.

\footnotetext{
${ }^{1}$ Italian irregular words are defined as words stressed at third or fourth syllable from last (e.g., rùvido, dòllaro, àbitano, dèlegano).
}

\section{VISUAL ATTENTIONAL TASKS}

\section{Spatial attention}

Testing was carried out in a dimly lit (luminance of $1.5 \mathrm{~cd} / \mathrm{m}^{2}$ ) and quiet room (approximately $50 \mathrm{~dB}$ SPL). Participants were seated in front of a computer screen (background luminance of $0.5 \mathrm{~cd} / \mathrm{m}^{2}$ ), with their head positioned on a chinrest so that the eye-screen distance was $40 \mathrm{~cm}$. Stimuli were white on a black background and had a luminance of $24 \mathrm{~cd} / \mathrm{m}^{2}$. Each trial started with the onset of the fixation point $\left(1^{\circ}\right.$ visual angle; $\left.500 \mathrm{~ms}\right)$. Two circles $\left(2.5^{\circ}\right)$ were displayed peripherally $\left(8^{\circ}\right.$ eccentricity, one to the left and one to the right of the fixation point) and $500 \mathrm{~ms}$ later the visual cue was shown, consisting of an arrow $\left(1.5^{\circ}\right.$ visual angle) displayed for $50 \mathrm{~ms}$ above one of the circles. In response trials, a target (dot, $0.5^{\circ}$; duration $50 \mathrm{~ms}$ ) was presented after one of two cue-target stimulus onset asynchronies (SOA, 100 or $350 \mathrm{~ms}$ ) in one of the two possible locations. The probability that the cue was presented in the target location was about $80 \%$ (i.e., the cue location was predictive of target location). In contrast, in catch trials the target was not presented and participants did not have to respond. Catch trials were intermixed with response trials. Participants were instructed to react as quickly as possible to the onset of the visual targets by pressing the spacebar on the computer keyboard (detection task). Simple RTs and error rates were recorded by the computer. The maximum time allowed to respond was $1500 \mathrm{~ms}$. The inter-trial interval was $1000 \mathrm{~ms}$, after that time the trial started automatically. The experimental session consisted of 128 trials divided into two blocks of 64 trials each, which were distributed as follows: 40 valid trials (20 targets in the right visual field and 20 in the left visual field, 10 for each SOA), 12 invalid trials ( 6 targets in the right visual field and 6 in the left visual field, 3 for each SOA), and 12 catch trials ( 6 for each SOA; see Figure 1).

\section{Temporal attention}

The experimental environment was the same as described above for the spatial attention task. Each trial began with the onset of the fixation mark $\left(0.3^{\circ}\right.$ of visual angle; duration $\left.500 \mathrm{~ms}\right)$. Participants were instructed to keep their eyes on the fixation mark throughout the duration of the trial. Two conditions, a "signal alone" $(\mathrm{O})$ and "signal + noise" ( $\mathrm{O}+$ noise $)$, were randomly presented to each participant. In the $\mathrm{O}$ condition a single object (duration $100 \mathrm{~ms}$ ) was displayed and the aim was to measure the participants' ability to identify the experimental stimuli. In the $\mathrm{O}+$ noise condition an 8 digital clock-face font comprising seven line segments was displayed for a variable time exposure $(175,225,275$, or $325 \mathrm{~ms}$ ) acting as a pre-mask, two successive objects (black $\mathrm{O} 1$ and red O2) were presented for $100 \mathrm{~ms}$ by removing some of the line segments (see Figure 2B, for stimuli used), each followed by a post-mask (8-digital clock-face font) of different duration (i.e., for $\mathrm{O} 1=50$ and for $\mathrm{O} 2=500 \mathrm{~ms}$ ). This condition was designed to maximize the load of the perceptual noise exclusion mechanism. All visual stimuli displayed had a luminance of $0.6 \mathrm{~cd} / \mathrm{m}^{2}$, the background appeared white and had a luminance of $119 \mathrm{~cd} / \mathrm{m}^{2}$. Participants viewed the sequence of stimuli binocularly and they were instructed to identify, at the end of each trial, $\mathrm{O}$ and $\mathrm{O} 1$ as accurately as possible, measuring the attentional engagement onto the target ( $\mathrm{O}$ and $\mathrm{O} 1)$. 
Before the start of the experimental session, participants viewed each of the four different stimuli one by one with no time constraint (familiarization phase). After each trial all four possible targets were presented on the screen together (two targets per line). Participants responded by pointing on the screen. These responses were registered by the experimenter by pressing the corresponding key on a computer keyboard and no feedback was provided. The experimental session consisted of 40 trials (16 for the $\mathrm{O}$ condition and 24 for the $\mathrm{O}+$ noise condition; see Figure 2).

\section{RESULTS}

\section{AGE, IO, READING, AND PHONOLOGICAL SKILLS: GROUPS ANALYSIS}

The differences between the three groups in age, Performance IQ, experimental reading paradigm (the accuracy in regular, irregular word, and pseudoword reading) and phonological tasks (pseudowords and phonemes correctly reported in the PPB and PSTM task, respectively) were analyzed. Results showed no significant differences in age or Performance IQ $[F<1$ and $F_{(1,72)}=1.94, p>0.05$, respectively], whereas significant differences were shown in all reading indexes [Regular words: $F_{(1,72)}=9.77, p<0.0001$; Irregular words: $F_{(1,72)}=9.86, p<$ 0.0001 ; and Pseudowords: $\left.F_{(1,72)}=54.14, p<0.0001\right]$ and in the two phonological tasks. The NR group demonstrated a significantly higher number of correctly pronounced pseudowords in the PPB task $\left[F_{(1,72)}=15.08, p<0.0001\right]$ and correctly pronounced phonemes in the PSTM task $\left[F_{(1,72)}=12.31, p<\right.$ $0.0001]$ compared to the two groups of dyslexic children. Planned comparisons demonstrated that, although both dyslexic groups were significantly different from NR in all reading and phonological abilities, DDP - and DDP + were different only in pseudoword reading accuracy (see Table $\mathbf{1}$ ). Thus, the selective deficit in phonological decoding skills observed in the DDP- group is difficult to explain with respect to differences in their phonological processing, which did not significantly differ between the two dyslexic groups (see Table 1).

\section{VISUAL ATTENTIONAL TASKS: GROUPS ANALYSIS Spatial attention}

Mean correct detection RTs were analyzed with a mixed ANOVA that had target condition (valid and invalid) and SOA (100 and $350 \mathrm{~ms}$ ) as within-subject factors, and group (NR, DDP+, and DDP-) as between-subject factor. The target condition main effect was significant, $F_{(1,72)}=69.85, p<0.0001$; RTs were slower in the invalid condition $(460 \mathrm{~ms})$ than in the valid condition $(423 \mathrm{~ms}$; cuing effect $=37 \mathrm{~ms}$ ). No other main effects were significant. Notably, the critical three-way interaction group $\times$ SOA $\times$ target condition interaction was significant, $F_{(2,72)}=$ 3.77, $p<0.05$ (see Figure 3), indicating a different time-course of attentional orienting in the three groups. At short SOA, both dyslexic groups, in the valid condition, appear to detect targets more slowly in comparison to the normal readers. These results show an apparently reduced facilitation effect in both dyslexic groups. In the invalid condition the DDP - group was similar to the NR group suggesting an unimpaired inhibition mechanism in the DDP - group. The DDP - group was faster than the $\mathrm{DDP}+$ in the invalid cue condition suggesting an abnormal inhibition mechanism in the DDP+ group. All three groups showed a significant cuing effect (i.e., invalid-valid RT differences) at $350 \mathrm{~ms}$ SOA $[\mathrm{NR}=37 \mathrm{~ms}(S D=39.26), \mathrm{DDP}+=$ $32 \mathrm{~ms}(S D=67.74)$, and $\mathrm{DDP}-=59 \mathrm{~ms} \quad(S D=62.91)$; all ps $<0.005$ ], demonstrating that they are able to orient spatial attention at the longer time interval. In contrast, only the DDPgroup did not show a significant cuing effect at the $100 \mathrm{~ms}$ SOA $[\mathrm{NR}=37 \mathrm{~ms}(S D=38.15), \mathrm{DDP}+=32 \mathrm{~ms}(S D=44.50)$, and $\mathrm{DDP}-=13 \mathrm{~ms}(S D=44.51)]$, demonstrating a sluggish VSA in DDP - in comparison to NR and DDP+ (see Table 2). Moreover, the DDP - group showed and amplified cuing effect in comparison to NR and DDP+ grouped together at $350 \mathrm{~ms} \mathrm{SOA}(p<0.05$; see Figure 4).

In summary, the data highlighted a marked offset of the timecourse of visual attention in DDP-, which suggests a sluggish VSA, because differences were selectively present only for the

Table 1 | Mean (M) and standard deviation (SD) of age (months), Performance IQ (Figure Completion, Wechsler, 1993), Reading abilities (Regular, Irregular words, and Pseudowords), pseudowords phoneme blending (number of correct pseudowords), and a pseudoword short-term memory (number of correct phonemes) in normally reading children (NR) and developmental dyslexics without (DDP+) and with (DDP-) phonological decoding deficit.

\begin{tabular}{|c|c|c|c|c|c|c|c|c|c|c|c|c|c|c|c|}
\hline & \multicolumn{2}{|c|}{$N R(N=43)$} & \multicolumn{2}{|c|}{$\mathrm{DDP}+(N=18)$} & \multicolumn{2}{|c|}{ DDP- $(N=14)$} & \multicolumn{3}{|c|}{$\begin{array}{l}\text { Comparison } \\
\text { NR vs. DDP+ }\end{array}$} & \multicolumn{3}{|c|}{$\begin{array}{l}\text { Comparison } \\
\text { NR vs. DDP- }\end{array}$} & \multicolumn{3}{|c|}{$\begin{array}{c}\text { Comparison } \\
\text { DDP+ vs. DDP- }\end{array}$} \\
\hline & $M$ & $S D$ & $M$ & $S D$ & $M$ & $S D$ & $t_{(59)}$ & $\boldsymbol{P}$ & C.'s d & $t_{(55)}$ & $\boldsymbol{P}$ & C.'s d & $t_{(30)}$ & $\boldsymbol{P}$ & C.'s d \\
\hline Age (months) & 122.23 & 27.87 & 122.50 & 20.00 & 122.57 & 25.45 & -0.04 & $>0.05$ & -0.01 & -0.04 & $>0.05$ & -0.01 & 0.01 & $>0.05$ & -0.003 \\
\hline Performance IQ (ss) & 13.65 & 2.61 & 12.11 & 3.41 & 13.07 & 2.43 & 1.17 & $>0.05$ & 0.51 & 0.76 & $>0.05$ & 0.23 & -0.93 & $>0.05$ & -0.32 \\
\hline Regular words reading (\%) & 99.67 & 0.75 & 90.56 & 15.76 & 93.57 & 3.16 & 2.45 & $<0.05$ & 0.82 & 7.17 & $<0.001$ & 2.66 & -0.80 & $>0.05$ & -0.26 \\
\hline $\begin{array}{l}\text { Number of correct } \\
\text { pseudowords }\end{array}$ & 5.44 & 1.76 & 3.50 & 2.75 & 2.18 & 1.99 & 2.77 & $<0.02$ & 0.84 & 5.46 & $<0.001$ & 1.73 & -1.57 & $>0.05$ & 0.55 \\
\hline $\begin{array}{l}\text { Number of correct } \\
\text { phonemes }\end{array}$ & 56.74 & 17.20 & 40.61 & 15.41 & 35.86 & 11.97 & 3.60 & $<0.002$ & 0.99 & 5.05 & $<0.001$ & 1.41 & -0.98 & $>0.05$ & 0.34 \\
\hline
\end{tabular}

The effect size (Cohen's d) is reported as C.'s $d$. 
shorter SOA. DDP - group show that for the longer SOA, VSA was abnormally oriented.

\section{Temporal attention}

The identification accuracy mean in the $\mathrm{O}$ condition was analyzed by a One-Way ANOVA with Group as the between subjects factor. The group main effect was not significant $\left[F_{(2,72)}=\right.$ 1.34, $p>0.05$ ], highlighting that signal identification in the DDP - group did not differ from either the NR or DDP+

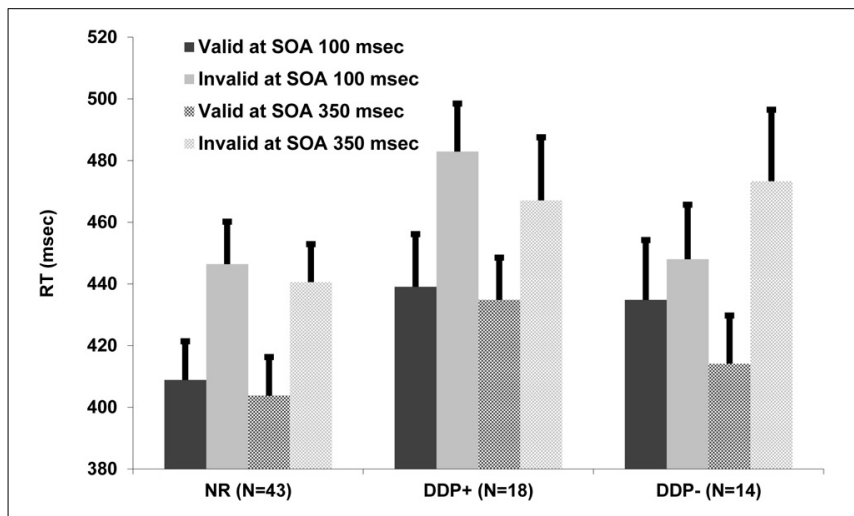

FIGURE 3 | Mean RT and standard error as a function of group (NR, DDP+, and DDP-), target condition (valid vs. invalid cue), and cue-target SOA (100 and $350 \mathrm{~ms}$ ).

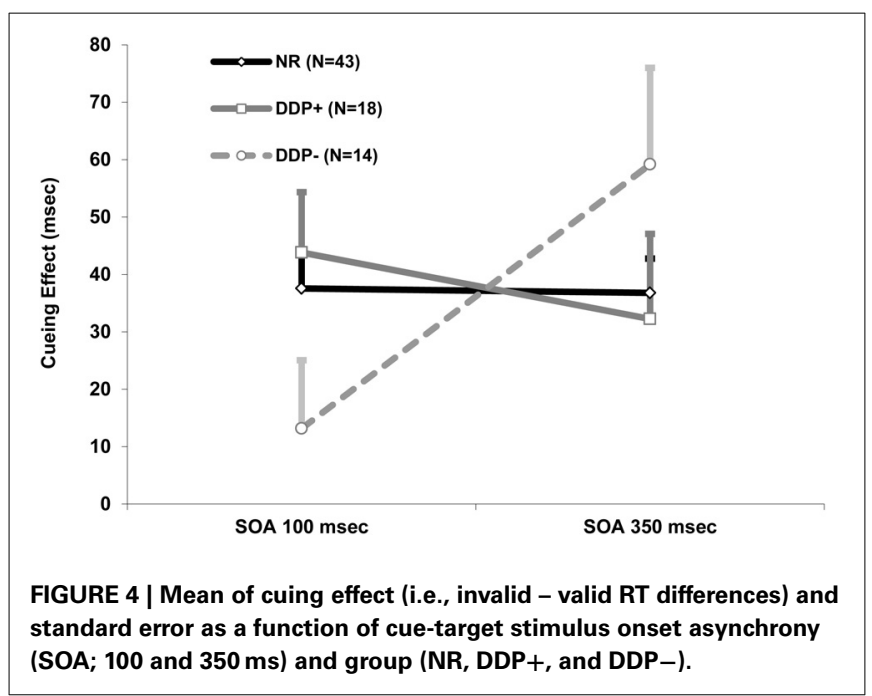

groups. In contrast, the mean $\mathrm{O} 1$ accuracy rate ${ }^{2}$ ANOVA showed a significant group effect $\left[F_{(2,72)}=3.23, p<0.05\right]$, demonstrating that signal identification in presence of noise was significantly impaired in DDP- $(47 \%)$, in comparison to NR (64\%) and DDP+ (64\%). Planned comparisons showed that the DDP - group, as compared to NR $\left[t_{(72)}=5.93, p<0.005\right]$ and DDP $+\left[t_{(72)}=4.84, p<0.05\right]$, was significantly impaired in signal identification when presented with noise (see Table 3 ). In order to test perceptual-noise exclusion mechanism, "intrusion" errors for the identity of the second target were analyzed by a 1-tailed Independent Sample Test, showing a higher incidence of identity intrusions in the DDP - group (mean = $42 \%, S D=11.22)$ compared to $\mathrm{NR}($ mean $=36 \%, S D=12.19)$, $p<0.05$ and DDP+ (mean $=34 \%, S D=10.97), p<0.05$ (details are reported in Table 4). In summary, our results showed that only dyslexics with phonological decoding deficit present difficulties in their perceptual-noise exclusion mechanism (see Figure 5).

\section{RELATIONSHIP BETWEEN VISUAL ATTENTION AND PHONOLOGICAL DECODING IN DYSLEXIC CHILDREN}

Our results demonstrate a specific VSA and VTA deficit in the DDP - group. In order to investigate a possible relationship between individual measures of the cuing effect (VSA) time-course, the perceptual noise exclusion mechanism (VTA), and phonological decoding skill across our entire sample of dyslexic children $(N=32)$, bivariate correlations were computed. Reading abilities were measured on regular words, irregular words and pseudowords. The time-course of VSA was indexed by the difference between the cuing effects at 350 and $100 \mathrm{~ms}$ SOA. The efficiency of the VTA corresponded to the identification

${ }^{2}$ The main effect of the O1 pre-mask variable time exposure $(175,225,275$ or $325 \mathrm{msec}$ ) and the interaction effect with the group were not significant (ps > 0.05).

Table 3 | Mean (M) and standard deviation (SD) of single object (O) and signal+noise $(\mathrm{O}+$ noise $)$.

\begin{tabular}{|c|c|c|c|c|c|c|}
\hline & \multicolumn{2}{|c|}{$N R(N=43)$} & \multicolumn{2}{|c|}{$\mathrm{DDP}+(N=18)$} & \multicolumn{2}{|c|}{ DDP- $(N=14)$} \\
\hline & $M$ & $S D$ & $M$ & $S D$ & $M$ & $S D$ \\
\hline O & 94 & 8.27 & 93 & 10.53 & 89.50 & 9.30 \\
\hline $\mathrm{O}+$ noise & 64 & 21.89 & 64 & 21.66 & 47 & 23.83 \\
\hline
\end{tabular}

Table 2 | Mean (M) and standard deviation (SD) of cuing effect at 100 and 350 ms cue-target delay.

\begin{tabular}{|c|c|c|c|c|c|c|c|c|c|c|c|c|c|c|c|}
\hline & \multicolumn{2}{|c|}{$N R(N=43)$} & \multicolumn{2}{|c|}{$\mathrm{DDP}+(N=18)$} & \multicolumn{2}{|c|}{ DDP- $(N=14)$} & \multicolumn{3}{|c|}{$\begin{array}{l}\text { Comparison } \\
\text { NR vs. DDP+ }\end{array}$} & \multicolumn{3}{|c|}{$\begin{array}{l}\text { Comparison } \\
\text { NR vs. DDP- }\end{array}$} & \multicolumn{3}{|c|}{$\begin{array}{c}\text { Comparison } \\
\text { DDP+ vs. DDP- }\end{array}$} \\
\hline & $M$ & $S D$ & $M$ & $S D$ & $M$ & $S D$ & $t_{(59)}$ & $P$ & C.'s d & $t_{(55)}$ & $\boldsymbol{P}$ & C.'s d & $t_{(30)}$ & $P$ & C.'s d \\
\hline 100 ms cue-target delay & 37.56 & 38.15 & 43.83 & 44.50 & 12.74 & 44.51 & -0.52 & $>0.05$ & -0.01 & 2.03 & $<0.05$ & 0.88 & 1.96 & $<0.05$ & 0.96 \\
\hline 350 ms cue-target delay & 36.79 & 39.26 & 32.25 & 67.74 & 59.19 & 62.91 & 0.27 & $>0.05$ & 0.08 & -1.26 & $>0.05$ & -0.43 & -1.15 & $>0.05$ & -0.41 \\
\hline
\end{tabular}

The Effect Size (Cohen's d) is reported as C.'s d. 

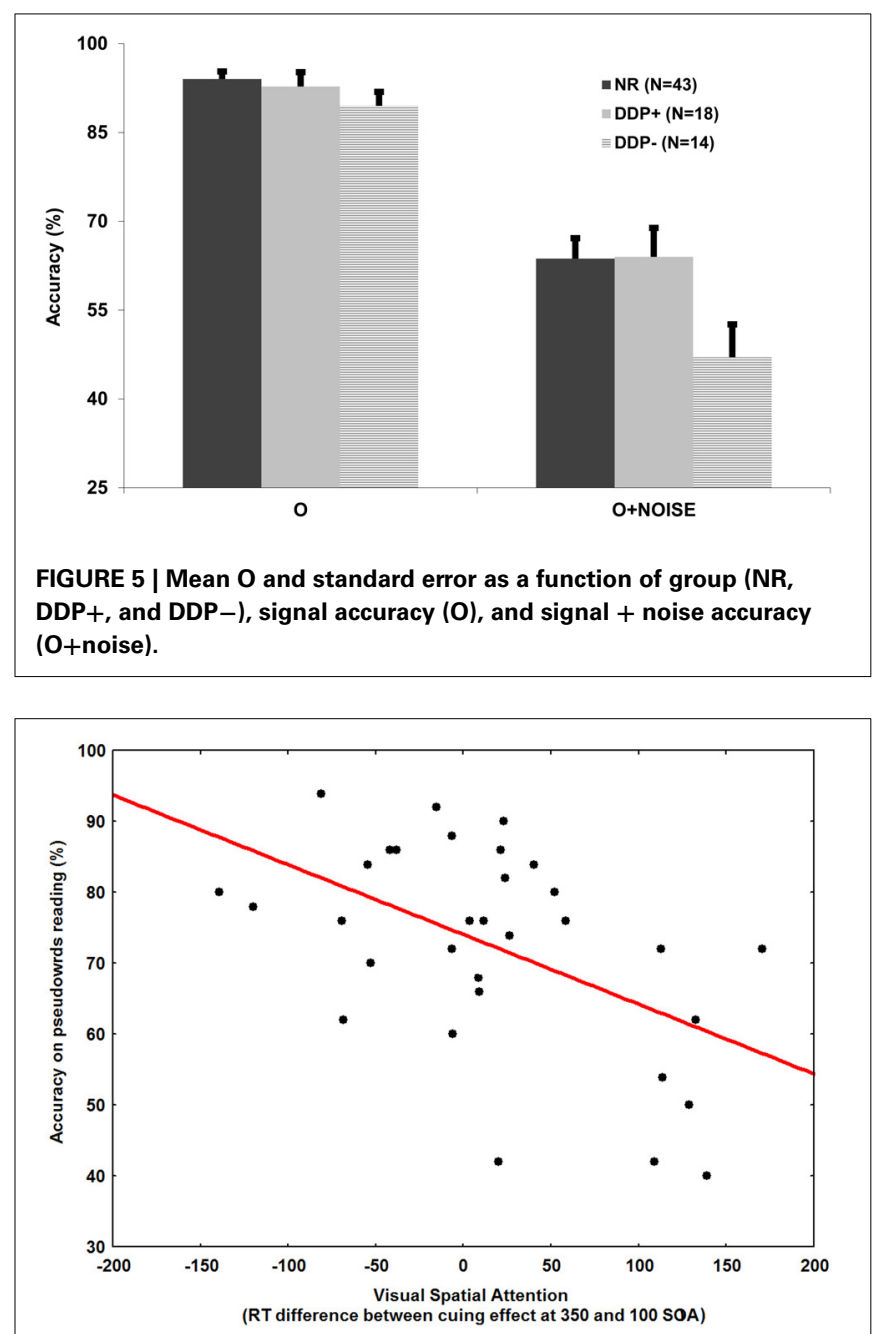

FIGURE 6 | Scatter plot of the relationship between time-course of visual spatial attention (RT difference between cuing effect at 350 and $100 \mathrm{~ms}$ SOA) and pseudoword reading accuracy across our entire sample of dyslexic children $(N=32)$.

accuracy mean in the $\mathrm{O}+$ noise condition. Phonological abilities were measured by using the efficiency in the PPB and PSTM tasks.

The main results showed that phonological decoding was significantly correlated with both spatial and temporal attention as well as phoneme blending (see Figures 6, 7). In addition, irregular word reading was correlated with both phonological tasks and VSA. Finally, temporal and spatial attention were highly correlated to each other (see Table 5A). The same bivariate correlations were computed in our entire sample $(N=75)$, including the NR children, confirming the relationship between visual attention and phonological decoding (see Table 5B).

To determine predictive relationships between visual attention and reading (pseudoword and irregular) accuracy, we computed two four-step fixed-entry multiple regression analyses on the individual data of the dyslexic children to control for the effects of age, Performance IQ, attentional mechanisms, and phonological processing. 


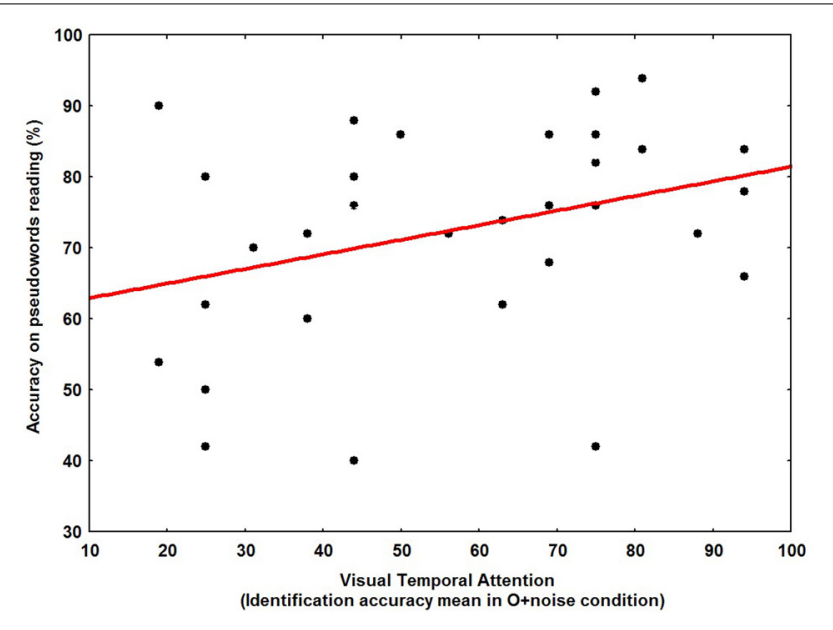

FIGURE 7 | Scatter plot of the relationship between visual temporal attention (identification accuracy mean in $\mathrm{O}+$ noise condition) and pseudoword reading accuracy across our entire sample of dyslexic children $(N=32)$.

Descriptive statistics of variables included in the multiple regression analysis are reported in Table 6. Because attentional graphemic parsing precedes phonemic blending during the reading process and VSA precedes the perceptual noise exclusion mechanism, we selected the following order of steps. In the first multiple regression analysis the dependent variable was pseudoword reading accuracy and the predictors entered at the four steps were: (i) age and Performance IQ, (ii) VSA, (iii) VTA, and (iv) PPB. Results showed that the time-course of spatial attention accounted for $17 \%$ $(p<0.02)$ of unique variance in sub-lexical reading accuracy. Only the PPB entered at the last step accounted for $14 \%$ $(p<0.05)$ of unique variance in lexical reading accuracy (see Table 7).

In the second multiple regression analysis the dependent variable was irregular word reading accuracy and the predictors entered at the four steps were the same as in the first analysis. Only the PPB entered at the last step accounted for $12 \%(p<0.05)$ of unique variance in lexical reading accuracy (see Table 8).

\section{DISCUSSION}

Our results demonstrate that both spatial and temporal attention were impaired only in dyslexics with a poor phonological decoding (DDP-), confirming the relationship between visual attentional mechanisms and graphemic parsing processes. It is important to note that attentional graphemic parsing precedes the letter-to-speech sound integration.

The attentional cuing effect was present at the shortest cuetarget delay $(100 \mathrm{~ms})$ in both $\mathrm{NR}$ and $\mathrm{DDP}+$, as predicted by automatic capture theories (for a review, see Klein, 2000). In contrast, DDP - children showed a slower visual-spatial attentional orienting, because the cuing effect was not present at the short cue-target delay (distributed attention) whereas it appears at the long cue-target delay, as predicted by the "SAS" theory (Hari and Renvall, 2001; Facoetti et al., 2010a; Lallier et al., 2010; see
Facoetti, 2012, for a recent review). We note that in DDP- the cuing effect was stronger than in DDP + and NR grouped together at the long cue-target delay, suggesting that poor phonological decoders present a more concentrated focus of attention on the cue. These findings could reconcile apparent contradictory results in the literature regarding the different size of the attentional focus in dyslexics. For example, according to some evidence the attentional focus appears more distributed in dyslexics in comparison to normally reading children (e.g., Geiger et al., 1994, 2008; Facoetti et al., 2000). In contrast, other studies have shown more focused attention in dyslexics in comparison to normally reading children (e.g., Bosse et al., 2007). In general, before the cue onset, the attentional focus - controlled by the right frontal eye fields (Ronconi et al., 2014) —is probably distributed across the possible target locations indicated by the two circles. The attentional focus of the poor phonological decoders will be on the cue location for long cue-target delay (cuing effect), whereas their attentional focus will not be there for short cue-target delay (absence of cuing effect), suggesting a sluggish attentional orienting (Facoetti et al., 2010a; see Hari and Renvall, 2001; Facoetti, 2012, for reviews). Once on the cue, the attentional focus appears more focused in comparison to the other two groups. This combination of spatial attention disorders probably impairs the serial letter processing during graphemic parsing.

Moreover, object identification in the object task without noise was not impaired in poor phonological decoders, excluding a possible general visual perception deficit. In contrast, DDPshowed a specific identification deficit in comparison to NR and $\mathrm{DDP}+$ when the object was displayed with noise (i.e., masks and a second object), demonstrating an inefficient perceptualnoise exclusion mechanism. Although the DDP- group showed a larger second object substitution, it would be important for future research to incorporate a baseline measure including O1+mask, but excluding $\mathrm{O} 2$, which would better isolate the role of specific $\mathrm{O} 2$ interference on $\mathrm{O} 1$. This condition could be relevant to even better isolate the pure role of the $\mathrm{O} 2$ interference, otherwise it would be difficult to exclude that unknown processing speed differences between the groups may play a role in the results.

According to the phonological hypothesis, it is important to note that poor pseudoword reading accuracy is strongly related to impaired phonological awareness (Frith, 1997; Snowling, 2000; Goswami, 2003, 2011; Vellutino et al., 2004). However, the two samples of dyslexics were not different in general phonological processing (i.e., phoneme blending and short-term memory of pseudowords). Only in DDP - both spatial and temporal attentional tasks were specifically disturbed, consistent with the hypothesis that SAS (Hari and Renvall, 2001) contributes to difficulties in phonological decoding, and it is at least partially independent from phonological skills (Bosse et al., 2007; Facoetti et al., 2010a,b; Franceschini et al., 2012, 2013; Zorzi et al., 2012; see Vidyasagar and Pammer, 2010, for a review).

Our attention indices allowed us to discriminate between dyslexics with poor phonological decoding and dyslexics with unimpaired phonological decoding or normal readers. Our results suggest that visual attention impairments are the core 
Table 5 | Bivariate correlations between abilities were measured on Regular and Irregular words and Pseudowords, time-course of visual spatial attention (VSA; RT difference between cuing effect at 350 and $100 \mathrm{~ms} \mathrm{SOA}$ ), time-course of visual temporal attention (VTA; identification accuracy mean in $\mathrm{O}+$ noise condition), pseudowords phoneme blending (number of correct pseudowords), and a pseudoword short term memory (number of correct phonemes).

\begin{tabular}{|c|c|c|c|c|c|c|}
\hline & $\begin{array}{l}\text { Regular words } \\
\text { reading }(\%)\end{array}$ & $\begin{array}{l}\text { Irregular words } \\
\text { reading }(\%)\end{array}$ & $\begin{array}{l}\text { Pseudowords } \\
\text { reading }(\%)\end{array}$ & $\begin{array}{c}\text { Number of correct } \\
\text { pseudowords }\end{array}$ & $\begin{array}{c}\text { Number of correct } \\
\text { phonemes }\end{array}$ & VTA \\
\hline \multicolumn{7}{|l|}{ (A) } \\
\hline Irregular words reading (\%) & $0.937^{* *}$ & - & & & & \\
\hline Pseudowords reading (\%) & $0.691^{* *}$ & $0.739 * *$ & - & & & \\
\hline Number of correct pseudowords & 0.336 & $0.436^{*}$ & $0.463^{* *}$ & - & & \\
\hline Number of correct phonemes & 0.172 & $0.350 *$ & 0.159 & $0.574^{* *}$ & - & \\
\hline VTA & 0.056 & 0.120 & $0.333^{*}$ & -0.063 & 0.012 & - \\
\hline VSA & -0.322 & $-0.374^{*}$ & $-0.476^{* *}$ & -0.239 & -0.325 & $-0.517 * *$ \\
\hline \multicolumn{7}{|l|}{ (B) } \\
\hline Irregular words reading (\%) & $0.932^{* *}$ & - & & & & \\
\hline Pseudowords reading (\%) & $0.717^{* *}$ & $0.743^{* *}$ & - & & & \\
\hline Number of correct pseudowords & $0.430 * *$ & $0.502 * *$ & $0.543^{* *}$ & - & & \\
\hline Number of correct phonemes & $0.301 * *$ & $0.439 * *$ & $0.372^{* *}$ & $0.613 * *$ & - & \\
\hline VTA & 0.117 & 0.206 & $0.310^{* *}$ & 0.168 & 0.181 & - \\
\hline VSA & $-0.267^{* *}$ & $-0.347^{* *}$ & $-0.267^{*}$ & -0.203 & $-0.255^{*}$ & $-0.295^{*}$ \\
\hline
\end{tabular}

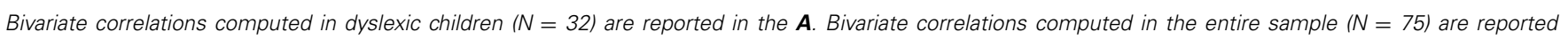
in the $\boldsymbol{B}$.

${ }^{*}$ Correlation is significant at the 0.05 level.

${ }^{*}$ Correlation is significant at the 0.01 level.

Table 6 | Descriptive Statistics of variables included in the multiple regression analysis: age (month), Performance IQ (Figure

Completion, Wechsler, 1993), pseudoword reading accuracy, time-course of visual spatial attention (VSA; RT difference between cuing effect at $\mathbf{3 5 0}$ and $\mathbf{1 0 0} \mathrm{ms}$ SOA) and time-course of visual temporal attention (VTA; identification accuracy mean in O+noise condition), and pseudowords phoneme blending (PPB; number of correct pseudowords) in dyslexic children $(N=32)$.

\begin{tabular}{lcc}
\hline & \multicolumn{2}{c}{ DD (N=32) } \\
\cline { 2 - 3 } & M & SD \\
\hline Age (months) & 122.53 & 22.16 \\
Performance IQ (ss) & 12.53 & 3.02 \\
Pseudowords reading (\%) & 72.5 & 14.70 \\
VSA & 13.81 & 79.50 \\
VTA & 56.59 & 23.84 \\
Number of correct phonemes & 38.53 & 14 \\
\hline
\end{tabular}

deficit in dyslexics characterized by poor (i.e., inaccurate) phonological decoding. This finding was supported by the predictive relationship of reading performance and visual attentional tasks, even after controlling for age and Performance IQ. Attentional graphemic parsing was significantly related to phonological decoding because it represents the first step that precedes not only letter-to-speech sound integration but also phonemic blending (significantly related to pseudoword reading) during the reading process.
It is important to stress that the predictive relationship between attention and reading skills held across the entire sample of dyslexics, independently of any a priori classification or subtyping of the dyslexic children. Thus, regardless of whether children in the DDP+ group constitute a specific subtype in shallow orthographies (Wimmer, 1993) or have partly compensated their reading deficit, rapid and efficient orienting of spatial attention seems to be related to phonological decoding. We suggest that this relationship might be causal because: (i) VSA is impaired in preschoolers at risk of DD (Facoetti et al., 2010b); (ii) it represents a significant predictor of future reading abilities (Franceschini et al., 2012); and (iii) attentional video games training has been proven to increase reading skills (Franceschini et al., 2013).

Our findings are consistent with previous results (e.g., Roach and Hogben, 2007; Facoetti et al., 2010a), and with the predictions of the CDP+ computational model of reading aloud (Perry et al., 2007). Efficient focused attention-indicated by a cuing effect at the short cue-target delay-is necessary for serial letter processing during phonological decoding, limiting the perceptual noise. In the DDP- group the cuing effect was absent at short cue-target delay, increasing the interference produced by perceptual noise during letter processing. Accordingly, several studies suggest that a general disorder in ignoring taskirrelevant information characterizes dyslexia perceptual processing (e.g., Badcock et al., 2008, 2011; Roach and Hogben, 2008). The sluggish attentional orienting index (spatial attention, task 1 ) is linked to a perceptual noise exclusion mechanism (temporal attention, task 2). The CDP+ assumes that focused attention is specifically involved in the sub-lexical spelling-to-sound mapping process (i.e., the sub-lexical route). Visual attentional tasks 
Table 7 | Multiple regression analysis with pseudoword reading accuracy as dependent variable and the following predictors entered at the four steps: (i) age and Performance IQ, (ii) time-course of visual spatial attention (VSA; RT difference between cuing effect at 350 and 100 ms SOA), (iii) time-course of visual temporal attention (VTA; difference between signal accuracy and signal + noise accuracy), and (iv) pseudowords phoneme blending (PPB; number of correct pseudowords) in dyslexic children $(N=32)$.

\begin{tabular}{|c|c|c|c|c|c|c|c|}
\hline \multirow[t]{2}{*}{ Predictors } & \multirow[t]{2}{*}{$\boldsymbol{R}$} & \multirow[t]{2}{*}{$R^{2}$} & \multicolumn{5}{|c|}{ Change Statistics } \\
\hline & & & $R^{2}$ Change & F Change & $d f 1$ & $d f 2$ & Sig. $F$ Change \\
\hline Age and performance 10 & 0.283 & 0.080 & 0.080 & 1.265 & 2 & 29 & $>0.05$ \\
\hline VSA & 0.501 & 0.251 & 0.171 & 6.380 & 1 & 28 & $<0.02$ \\
\hline VTA & 0.506 & 0.256 & 0.005 & 0.187 & 1 & 27 & $>0.05$ \\
\hline PPB & 0.628 & 0.394 & 0.138 & 5.908 & 1 & 26 & $<0.05$ \\
\hline
\end{tabular}

Table 8 | Multiple regression analysis with irregular word reading accuracy as the dependent variable and the following predictors entered at the four steps: (i) age and Performance IQ, (ii) time-course of visual spatial attention (VSA; RT difference between cuing effect at 350 and $100 \mathrm{~ms}$ SOA), (iii) time-course of visual temporal attention (VTA; difference between signal accuracy and signal + noise accuracy), and (iv) pseudowords phoneme blending (PPB; number of correct pseudowords) in dyslexic children ( $N=32$ ).

\begin{tabular}{|c|c|c|c|c|c|c|c|}
\hline \multirow[t]{2}{*}{ Predictors } & \multirow[t]{2}{*}{$\boldsymbol{R}$} & \multirow[t]{2}{*}{$R^{2}$} & \multicolumn{5}{|c|}{ Change Statistics } \\
\hline & & & $R^{2}$ Change & F Change & df1 & $d f 2$ & Sig. $F$ Change \\
\hline Age and performance $1 \mathrm{Q}$ & 0.266 & 0.071 & 0.071 & 1.102 & 2 & 29 & $>0.05$ \\
\hline VSA & 0.402 & 0.162 & 0.072 & 0.091 & 1 & 28 & $>0.05$ \\
\hline VTA & 0.438 & 0.192 & 0.030 & 1.006 & 1 & 27 & $>0.05$ \\
\hline PPB & 0.556 & 0.309 & 0.117 & 4.381 & 1 & 26 & $<0.05$ \\
\hline
\end{tabular}

accounted almost for $20 \%$ of unique variance in phonological decoding, representing an excellent predictor of pseudoword reading. Moreover, irregular word reading accuracy was not significantly predicted by the visual attentional variables, but only by the phonological ones (which accounted for $12 \%$ ).

Clearly, these results are inconsistent with the hypothesis that DD is an exclusively phonological deficit. The present link between deficits in spatial and temporal attention and impaired phonological decoding is consistent with the hypothesis that visual selection (i.e., the perceptual-noise exclusion mechanism) operates on graphemes as the basic component of the phonological assembly process (Cestnick and Coltheart, 1999; Perry et al., 2007, Gori et al., under revision in the same issue). Both spatial (Geiger and Lettvin, 1987; Sperling et al., 2005; Geiger et al., 2008) and temporal (Di Lollo et al., 1983; Visser et al., 2004; Montgomery et al., 2005; Facoetti et al., 2008) processing windows in which noise interferes with the signal appear to be broader in dyslexics than normally reading children. In this study, we demonstrated that these deficits are specific in poor phonological decoders, and this can be attributed to the perceptual-noise exclusion deficit (Sperling et al., 2005). The link between deficits in VSA and impaired phonological decoding is also consistent with the results of recent studies in dyslexics that used visual search paradigms (e.g., Buchholz and McKone, 2004; Roach and Hogben, 2007; Jones et al., 2008; Facoetti et al., 2010a; Vidyasagar and Pammer, 2010, for a review). Furthermore, our results demonstrate, for the first time, that the relationship between visual attention and phonological decoding skills in dyslexia is explained by a sluggish shifting of spatial attention rather than a general perceptual noise exclusion mechanism. We suggest that inefficient spatial attention could specifically impair the graphemic parsing mechanism in dyslexic children. Although our spatial attention task involves also a temporal component, several studies have shown that the rapid shift of spatial attention modulates the speed of processing and consequentially the temporal aspects of attention (e.g., Carrasco and McElree, 2001; Carrasco et al., 2002, 2004; see Enns and Di Lollo, 2000, for a review). However, further studies are necessary to investigate the specific relationship between spatial and temporal attention. The results of the present study do not speak to the issue of visual vs. auditory and phonological processing deficits in DD. Several authors have argued that the core problem in DD is a deficit in phonological representation (Snowling, 2000; Ramus, 2003). It is important to note that efficient learning of sub-lexical spellingsound mappings requires not only graphemic parsing but also accurate auditory and speech-sound segmentation mechanisms (see Goswami, 2003, 2011, for reviews). In particular, rise times are crucial events in the speech signal, as they reflect the patterns of amplitude modulation that facilitates the temporal segmentation of the acoustic signal into syllables. Rise time discrimination is impaired in dyslexia in English, French, Hungarian, Spanish, Chinese, and Finnish (Goswami, 2011). Rise time is a significant predictor of phonological awareness. However, efficient acoustic processing and segmentation of the speech signal are likely to require the rapid engagement of auditory attention (Renvall and Hari, 2002; Facoetti et al., 2003, 2005, 2010a). Auditory attention is, indeed, necessary for speech segmentation based on statistical learning (Toro et al., 2005) and for learning phonetic discriminations based on acoustic cues (Gordon et al., 1993; Francis et al., 2008; but see also Seitz et al., 2010). Moreover, auditory spatial 
attention has been shown to be defective in children with specific language impairment (SLI; Stevens et al., 2006) and reading DD (Asbjørnsen and Bryden, 1998; Renvall and Hari, 2002; Facoetti et al., 2003, 2005, 2010a,b).

Neural coding by brain oscillations is a major focus in neuroscience (e.g., Buzsaki and Draghun, 2004; Schroeder et al., 2008), with important implications for DD research (see Goswami, 2011, for a recent review). The results could be interpreted inside the oscillatory "temporal sampling" framework which is a compelling and robust theoretical framework (Goswami, 2011). Temporal sampling of speech-sound by neuroelectric oscillations that encode incoming information at different frequencies could explain the perceptual and phonological difficulties with syllables, rhymes and phonemes found in individuals with DD. A temporal sampling framework based on oscillations that entrain to sensory input could also have implications for other sensory theories of DD such as the magnocellular-dorsal (M-D) deficit theory (see Stein and Walsh, 1997; Gori and Facoetti, 2013, for a recent review). Thus, we conclude that a temporal sampling disorder of neural oscillations could characterize DD, suggesting innovative training programs not only for treatment but also for the possible prevention of $\mathrm{DD}$ at the pre-reading stage.

\section{ACKNOWLEDGMENTS}

This work was supported by a grant from University of Padua ("Progetto di Ateneo 2009 and 2011" to Andrea Facoetti and "Assegni di Ricerca 2009 and 2011" to Simone Gori). The contributions of the staff members of Eugenio Medea Scientific Institute as well as of the children and their families are gratefully acknowledged. We thank Marc Pomplun for his reading of the manuscript.

\section{SUPPLEMENTARY MATERIAL}

The Supplementary Material for this article can be found online at: http://www.frontiersin.org/journal/10.3389/fnhum. 2014.00331/abstract

\section{REFERENCES}

American Psychiatric Association. (1994). Diagnostic and Statistical Manual of Mental Disorders, 4th Edn. Washington, DC: DSM-IV.

American Psychiatric Association. (2013). Diagnostic and Statistical Manual of Mental Disorders, 5th Edn. Arlington, VA: American Psychiatric Publishing.

Asbjørnsen, A. E., and Bryden, M. P. (1998). Auditory attentional shifts in readingdisabled students: quantification of attentional effectiveness by Attentional Shift Index. Neuropsychologia 36, 143-148. doi: 10.1016/S0028-3932(97) 00090-0

Badcock, N. A., Hogben, J. H., and Fletcher, J. F. (2008). No differential attentional blink in dyslexia after controlling for baseline sensitivity. Vision Res. 48, 1497-1502. doi: 10.1016/j.visres.2008.03.008

Badcock, N. A., Hogben, J. H., and Fletcher, J. F. (2011). Dyslexia and practice in the attentional blink: evidence of slower task learning in dyslexia. Cortex 47, 494-500. doi: 10.1016/j.cortex.2010.03.002

Blau, V., Reithler, J., van Atteveldt, N., Seitz, J., Gerretsen, P., Goebel, R., and Blomert, L. (2010). Deviant processing of letters and speech sounds as proximate cause of reading failure: a functional magnetic resonance imaging study of dyslexic children. Brain 133, 868-879. doi: 10.1093/brain/ awp308

Blau, V., van Atteveldt, N., Ekkebus, M., Goebel, R., and Blomert, L. (2009). Reduced neural integration of letters and speech sounds links phonological and reading deficits in adult dyslexia. Curr. Biol. 19, 503-508. doi: 10.1016/j.cub.2009.01.065
Blomert, L. (2011). The neural signature of orthographic-phonological binding in successful and failing reading development. Neuroimage 57, 695-703. doi: 10.1016/j.neuroimage.2010.11.003

Bosse, M. L., Tainturier, M. J., and Valdois, S. (2007). Developmental dyslexia: The visual attention span deficit hypothesis. Cognition 104, 198-230. doi: 10.1016/j.cognition.2006.05.009

Bouma, H. (1970). Interaction effects in parafoveal letter recognition. Nature 226, 177-178. doi: 10.1038/226177a0

Bouma, H., and Legein, C. P. (1977). Foveal and parafoveal recognition of letters and words by dyslexics and by average readers. Neuropsychologia 15, 69-80. doi: 10.1016/0028-3932(77)90116-6

Boyer, J., and Ro, T. (2007). Attention attenuates metacontrast masking. Cognition 104, 135-149. doi: 10.1016/j.cognition.2006.06.001

Bradley, L., and Bryant, P. (1983). Categorizing sound and learning to read: a casual connection. Nature 301, 419-421. doi: 10.1038/301419a0

Braun, J. (2002). Visual attention: light enters the jungle. Curr. Biol. 12, 599-601. doi: 10.1016/S0960-9822(02)01103-X

Breznitz, Z., Shaul, S., Horowitz-Kraus, T., Sela, I., Nevat, M., and Jarni, A. (2013). Enhanced reading by training with imposed time constraint in typical and dyslexic adults. Nat. Commun. 4, 1486. doi: 10.1038/ncomms 2488

Buchholz, J., and McKone, E. (2004). Adults with dyslexia show deficits on spatial frequency doubling and visual attention tasks. Dyslexia 10, 24-43. doi: $10.1002 /$ dys. 263

Buzsaki, G., and Draghun, A. (2004). Neuronal oscillations in cortical networks. Science 25, 1926-1929. doi: 10.1126/science. 1099745

Carrasco, M., Ling, S., and Read, S. (2004). Attention alters appearance. Nat. Neurosci. 7, 308-313. doi: 10.1038/nn1194

Carrasco, M., and McElree, B. (2001). Covert attention accelerates the rate of visual information processing. Proc. Natl. Acad. Sci. U.S.A. 98, 5363-5367. doi: 10.1073/pnas.081074098

Carrasco, M., Penpeci-Talgar, C., and Eckstein, M. (2000). Spatial covert attention increases contrast sensitivity across the CSF: support for signal enhancement. Vision Res. 40, 1203-1215. doi: 10.1016/S0042-6989(00)00024-9

Carrasco, M., Williams, P., and Yeshurum, Y. (2002). Covert attention increases spatial resolution with or without masks: support for signal enhancement. J. Vis. 2, 467-479. doi: 10.1167/2.6.4

Castiello, U., and Umiltà, C. (1990). Size of the attentional focus and efficiency of processing. Acta Psychol. (Amst) 73, 195-209. doi: 10.1016/00016918(90)90022-8

Castles, A., and Coltheart, M. (1993). Varieties of developmental dyslexia. Cognition 47, 148-180. doi: 10.1016/0010-0277(93)90003-E

Castles, A., and Coltheart, M. (2004). Is there a causal link from phonological awareness to success in learning to read? Cognition 91, 77-111. doi: 10.1016/S0010-0277(03)00164-1

Cestnick, L., and Coltheart, M. (1999). The relationship between languageprocessing and visual processing deficit in developmental dyslexia. Cognition 71, 231-255. doi: 10.1016/S0010-0277(99)00023-2

Chandrasekaran, B., Hornickel, J., Skoe, E., Trent, N., and Kraus, N. (2009). Context-dependent encoding in the human auditory brainstem relates to hearing speech in noise: implications for developmental dyslexia. Neuron 64, 311-319. doi: 10.1016/j.neuron.2009.10.006

Dehaene, S., Pegado, F., Braga, L. W., Ventura, P., Nunes Filho, G., Jobert, A., et al. (2010). How learning to read changes the cortical networks for vision and language. Science 330, 1359-1364. doi: 10.1126/science.1194140

Di Lollo, V., Hanson, D., and McIntyre, J. S. (1983). Initial stages of visual information processing in dyslexia. J. Exp. Psychol. Hum. Percept. Perform. 6, 923-935. doi: 10.1037/0096-1523.9.6.923

Dispaldro, M., Laurence, B. L., Corradi, N., Ruffino, M., Bronte, T., and Facoetti, A. (2013). Visual attentional engagement deficits in children with Specific Language Impairment and their role in real-time language processing. Cortex 49, 2126-2139. doi: 10.1016/j.cortex.2012.09.012

Dosher, B. N., and Lu, Z. (2000). Noise exclusion in spatial attention. Psychol. Sci. 11, 139-146. doi: 10.1111/1467-9280.00229

Duncan, J., Ward, R., and Shapiro, K. (1994). Direct measurement of attentional dwell time in human vision. Nature 369, 313-315. doi: 10.1038/369313a0

Enns, J. T., and Di Lollo, V. (2000). What's new in visual masking? Trends Cogn. Sci. 4, 345-352. doi: 10.1016/S1364-6613(00)01520-5

Facoetti, A. (2012). "Spatial attention disorders in developmental dyslexia: towards the prevention of reading acquisition deficits," in Visual Aspect of Dyslexia, 
eds J. Stein and Z. Kapoula (Oxford, UK: Oxford University Press). doi: 10.1093/acprof:oso/9780199589814.003.0008

Facoetti, A., Corradi, N., Ruffino, M., Gori, S., and Zorzi, M. (2010b). Visual spatial attention and speech segmentation are both impaired in preschoolers at familial risk for developmental dyslexia. Dyslexia 16, 226-239. doi: 10.1002/dys.413

Facoetti, A., Lorusso, M. L., Cattaneo, C., Galli, R., and Molteni, M. (2005). Visual and auditory attentional capture are both sluggish in children with developmental dyslexia. Acta Neurobiol. Exp. 65, 61-72.

Facoetti, A., Lorusso, M. L., Paganoni, P., Umiltà, C., and Mascetti, G. G. (2003). The role of visuospatial attention in developmental dyslexia: evidence from a rehabilitation study. Cogn. Brain Res. 15, 15-164. doi: 10.1016/S09266410(02)00148-9

Facoetti, A., and Molteni, M. (2000). Is attentional focusing an inhibitory process at distractor location? Cogn. Brain Res. 10, 185-188. doi: 10.1016/S09266410(00)00031-8

Facoetti, A., Paganoni, P., and Lorusso, M. L. (2000). The spatial distribution of visual attention in developmental dyslexia. Exp. Brain Res. 132, 531-538. doi: $10.1007 / \mathrm{s} 002219900330$

Facoetti, A., Ruffino, M., Peru, A., Paganoni, P., and Chelazzi, L. (2008). Sluggish engagement and disengagement of non-spatial attention in dyslexic children. Cortex 44, 1221-1233. doi: 10.1016/j.cortex.2007.10.007

Facoetti, A., Trussardi, A. N., Ruffino, M., Lorusso, M. L., Cattaneo, C., Galli, R., et al. (2010a). Multisensory spatial attention deficits are predictive of phonological decoding skills in development dyslexia. J. Cogn. Neurosci. 22, 1011-1025. doi: 10.1162/jocn.2009.21232

Facoetti, A., Zorzi, M., Cestnick, L., Lorusso, M. L., Molteni, M., Paganoni, P., et al. (2006). The relationship between visuo spatial attention and nonword reading in developmental dyslexia. Cogn. Neuropsychol. 23, 841-855. doi: $10.1080 / 02643290500483090$

Farmer, M. E., and Klein, R. M. (1995). The evidence for a temporal processing deficit linked to dyslexia. Psychon. Bull. Rev. 2, 469-493. doi 10.3758/BF03210983

Franceschini, S., Gori, S., Ruffino, M., Pedrolli, K., and Facoetti, A. (2012). A causal link between visual spatial attention and reading acquisition. Curr. Biol. 22, 814-819. doi: 10.1016/j.cub.2012.03.013

Franceschini, S., Gori, S., Ruffino, M., Viola, S., Molteni, M., and Facoetti, A. (2013). Action video games make dyslexic children read better. Curr. Biol. 23, 1-5. doi: 10.1016/j.cub.2013.01.044

Francis, A. L., Kaganovich, N., and Driscoll-Huber, C. (2008). Cue-specific effects of categorization training on the relative weighting of acoustic cues to consonant voicing in English. J. Acoust. Soc. Am. 124, 1234-1251. doi: 10.1121/1.2945161

Frith, U. (1997). "Brain, mind and behaviour in dyslexia," in Dyslexia: Biology, Cognition and Intervention, eds C. Hulme and M. Snowling (London: Whurr), 1-19.

Gabrieli, J. D. (2009). Dyslexia: a new synergy between education and cognitive neuroscience. Science 325, 280-283. doi: 10.1126/science.1171999

Geiger, G., Cattaneo, C., Galli, R., Pozzoli, U., Lorusso, M. L., Facoetti, A., et al. (2008). Wide and diffuse perceptual modes characterized dyslexics in vision and audition. Perception 37, 1745-1764. doi: 10.1068/p6036

Geiger, G., and Lettvin, J. Y. (1987). Peripheral vision in persons with dyslexia. N. Engl. J. Med. 316, 1238-1243. doi: 10.1056/NEJM198705143162003

Geiger, G., Lettvin, J. Y., and Fanhle, M. (1994). Dyslexic children learn a new visual strategy for reading: a controlled experiment. Vision Res. 34, 1223-1233. doi: 10.1016/0042-6989(94)90303-4

Gordon, P. C., Eberhardt, J. L., and Rueckl, J. G. (1993). Attentional modulation of the phonetic significance of acoustic cues. Cogn. Psychol. 25, 1-42. doi: 10.1006/cogp.1993.1001

Gori, S., and Facoetti, A. (2013). Perceptual learning as a possible new approach for remediation and prevention of developmental dyslexia. Vision Res. doi: 10.1016/j.visres.2013.11.011. [Epub ahead of print].

Goswami, U. (2003). Why theories about developmental dyslexia require developmental designs. Trends Cogn. Sci. 7, 534-540. doi: 10.1016/j.tics.2003. 10.003

Goswami, U. (2011). A temporal sampling framework for developmental dyslexia. Trends Cogn. Sci. 15, 3-10. doi: 10.1016/j.tics.2010.10.001

Goswami, U., Thomson, J., Richardson, U., Strainthorp, R., Hughes, D., Rosen, S., et al. (2000). Amplitude envelope onsets and developmental dyslexia: A new hypothesis. Proc. Natl. Acad. Sci. U.S.A. 99, 10911-10916. doi: $10.1073 /$ pnas. 122368599
Hari, R., and Kiesilä, P. (1996). Deficit of temporal auditory processing in dyslexic adults. Neurosci. Lett. 23, 138-140. doi: 10.1016/0304-3940(96)12393-4

Hari, R., and Renvall, H. (2001). Impaired processing of rapid stimulus sequences in dyslexia. Trends Cogn. Sci. 5, 525-532. doi: 10.1016/S1364-6613(00)01801-5

Hari, R., Renvall, H., and Tanskanen, T. (2001). Left minineglect in dyslexic adults. Brain 124, 1373-1380. doi: 10.1093/brain/124.7.1373

Hari, R., Valta, M., and Uutella, K. (1999). Prolonged attentional dwell time in dyslexic adults. Neurosci. Lett. 271, 202-204. doi: 10.1016/S03043940(99)00547-9

Helenius, P., Uutela, K., and Hari, R. (1999). Auditory stream segregation in dyslexic adults. Brain 122, 907-913. doi: 10.1093/brain/122.5.907

Hornickel, J., Zecker, S. G., Bradlow, A. R., and Kraus, N. (2012). Assistive listening devices drive neuroplasticity in children with dyslexia. Proc. Natl. Acad. Sci. U.S.A. 109, 16731-16736. doi: 10.1073/pnas.1206628109

Jones, M. W., Branigan, H. P., Parra, M. A., and Logie, R. H. (2013). Crossmodal binding in developmental dyslexia. J. Exp. Psychol. Learn. Mem. Cogn. 39, 1807-1822. doi: 10.1037/a0033334

Jones, M. W., Branigan, H. P., and Kelly, M., L. (2008). Visual deficits in developmental dyslexia: relationships between non-linguistic visual tasks and their contribution to literacy. Dyslexia 14, 95-115. doi: 10.1002/dys.345

Jonides, J., and Yantis, S. (1998). Uniqueness of abrupt visual onset in capturing attention. Percept. Psychophys. 43, 346-354. doi: 10.3758/BF03208805

Klein, R. M. (2000). Inhibition of return. Trends Cogn. Sci. 4, 138-147. doi: 10.1016/S1364-6613(00)01452-2

LaBerge, D. (1995). Attentional Processing: The Brain's Art of Mindfulness. Cambridge, MA: Harvard University Press. doi: 10.4159/harvard. 9780674183940

Lallier, M., Tainturier, M. J., Dering, B., Donnadieu, S., Valdois, S., and Thierry, G. (2010). Behavioral and ERP evidence for amodal sluggish attentional shifting in developmental dyslexia. Neuropsychologia 48, 4125-4135. doi: 10.1016/j.neuropsychologia.2010.09.027

Montgomery, C. R., Morris, R. D., Sevcik, R. A., and Clarkson, M. G. (2005). Auditory backward masking deficits in children with reading disabilities. Brain Lang. 95, 450-456. doi: 10.1016/j.bandl.2005.03.006

Perry, C., Ziegler, J. C., and Zorzi, M. (2007). Nested incremental modeling in the development of computational theories: the CDP+ model of reading aloud. Psychol. Rev. 114, 273-315. doi: 10.1037/0033-295X.114.2.273

Peterson, R. L., and Pennington, B. F. (2012). Developmental dyslexia. Lancet 379, 1997-2007. doi: 10.1016/S0140-6736(12)60198-6

Plaza, M., and Cohen, H. (2007). The contribution of phonological awareness and visual attention in early reading and spelling. Dyslexia $13,67-76$. doi: $10.1002 /$ dys. 330

Posner, M. I. (1980). Orienting of attention. Q. J. Exp. Psychol. 32, 3-25. doi $10.1080 / 00335558008248231$

Ramus, F. (2003). Developmental dyslexia: specific phonological deficit or general sensorimotor dysfunction? Curr. Opin. Neurobiol. 13, 212-218. doi: $10.1016 /$ S0959-4388(03)00035-7

Renvall, H., and Hari, R. (2002). Auditory cortical responses to speech-like stimuli in dyslexic adults. J. Cogn. Neurosci. 14, 757-768. doi: 10.1162/08989290260 138654

Reynolds, J. H., and Chelazzi, L. (2004). Attentional modulation of visual processing. Annu. Rev. Neurosci. 27, 611-647. doi: 10.1146/annurev.neuro.26.041002. 131039

Roach, N. W., and Hogben, J. H. (2007). Impaired filtering of behaviourally irrelevant visual information in dyslexia. Brain 130, 771-785. doi: 10.1093/brain/awl353

Roach, N. W., Hogben, J. H. (2008). Spatial cueing deficits in dyslexia reflect generalised difficulties with attentional selection. Vision Res. 48, 193-207. doi: 10.1016/j.visres.2007.11.001

Ronconi, L., Basso, D., Gori, S., and Facoetti, A. (2014). tms on right frontal eye fields induces an inflexible focus of attention. Cereb. Cortex 24, 396-402. doi: $10.1093 /$ cercor/bhs319

Ronconi, L., Gori, S., Giora, E., Ruffino, M., Molteni, M., and Facoetti, A. (2013b). Deeper attentional masking by lateral objects in children with autism. Brain Cogn. 82, 213-218. doi: 10.1016/j.bandc.2013.04.006

Ronconi, L., Gori, S., Ruffino, M., Franceschini, S., Urbani, B., Molteni, M., and Facoetti, A. (2012). Decreased coherent motion discrimination in autism spectrum disorder: the role of attentional zoom-out deficit. PLoS ONE 7:e49019. doi: 10.1371/journal.pone.0049019 
Ronconi, L., Gori, S., Ruffino, M., Molteni, M., and Facoetti, A. (2013a). Zoom-out attentional impairment in children with autism spectrum disorder. Cortex 49, 1025-1033. doi: 10.1016/j.cortex.2012.03.005

Ruffino, M., Trussardi, A. N., Gori, S., Finzi, A., Giovagnoli, S., Menghini, D., et al. (2010). Attentional engagement deficits in dyslexic children. Neuropsychologia 48, 3793-3801. doi: 10.1016/j.neuropsychologia.2010.09.002

Sartori, G., Job, R., and Tressoldi, P. E. (1995). Batteria per la Valutazione Della Dislessia e Della Disortografia Evolutiva. Firenze: Giunti O.S. Organizzazioni Speciali.

Schneps, M. H., Thomson, J. M., Chen, C., Sonnert, G., and Pomplun, M. (2013a). E-readers are more effective than paper for some with dyslexia. PLoS ONE 18:e75634. doi: 10.1371/journal.pone.0075634

Schneps, M. H., Thomson, J. M., Sonnert, G., Pomplun, M., Chen, C., and HeffnerWong, A. (2013b). Shorter lines facilitate reading in those who struggle. PLoS ONE 5:e71161. doi: 10.1371/journal.pone.0071161

Schroeder, C. E., Lakatos, P., Kajikawa, Y., Partan, S., and Puce, A. (2008). Neuronal oscillations and visual amplification of speech. Trends Cogn. Sci. 12, 106-113. doi: 10.1016/j.tics.2008.01.002

Seitz, A. R., Protopapas, A., Tsushima, Y., Vlahou, E. L., Gori, S., Grossberg, S., et al. (2010). Unattended exposure to components of speech sounds yields same benefits as explicit auditory training. Cognition 115, 435-43. doi: 10.1016/j.cognition.2010.03.004

Share, D. L. (1995). Phonological recoding and self-teaching: sine qua non of reading acquisition. Cognition 55, 151-218. doi: 10.1016/0010-0277(94)00645-2 Snowling, M. J. (2000). Dyslexia. Oxford: Blackwell.

Sperling, A. J., Lu, Z. L., Manis, F. R., and Seidenberg, M. S. (2005). Deficits in perceptual noise exclusion in developmental dyslexia. Nat. Neurosci. 8, 862-863. doi: $10.1038 / \mathrm{nn} 1474$

Sprenger-Charolles, L., Siegel, L. S., Bechennec, D., and Serniclaes, W. (2003). Development of phonological and orthographic processing in reading aloud, in silent reading, and in spelling: a four-year longitudinal study. J. Exp. Child Psychol. 84, 194-217. doi: 10.1016/S0022-0965(03)00024-9

Stein, J., and Walsh, V. (1997). To see but not to read; the magnocellular theory of dyslexia. Trends Neurosci. 20, 147-152. doi: 10.1016/S0166-2236(96) 01005-3

Stevens, C., Sanders, L., and Neville, H. (2006). Neurophysiological evidence for selective auditory attention deficits in children with specific language impairment. Brain Res. 1111, 143-152. doi: 10.1016/j.brainres.2006. 06.114

Tallal, P. (1980). Auditory temporal perception, phonetic, and reading disabilities in children. Brain Lang. 9, 182-198. doi: 10.1016/0093-934X(80)90139-X

Tallal, P. (2004). Improving language and literacy is a matter of time. Nat. Rev. Neurosci. 5, 721-728. doi: 10.1038/nrn1499

Toro, J. M., Sinnet, S., Soto-Faraco, S. (2005). Speech segmentation by statistical learning depends on attention. Cognition 97, 25-34. doi: 10.1016/j.cognition. 2005.01.006

Vandermosten, M., Boets, B., Luts, H., Poelmans, H., Golestani, N., Wouters, J., et al. (2010). Adults with dyslexia are impaired in categorizing speech and nonspeech sounds on the basis of temporal cues. Proc. Natl. Acad. U.S.A. 107, 10389-10394. doi: 10.1073/pnas.0912858107
Vellutino, F. R., Fletcher, J. M., Snowling, M. J., and Scanlon, D. M. (2004). Specific reading disability (dyslexia): what have we learned in the past four decades? J. Child Psychol. Psychiatry 45, 2-40. doi: 10.1046/j.0021-9630.2003.00305.x

Vidyasagar, T. R., and Pammer, K. (2010). Dyslexia: a deficit in visuo-spatial attention, not in phonological processing. Trends Cogn. Sci. 14, 57-63. doi: 10.1016/j.tics.2009.12.003

Visser, T. A. W., Boden, C., and Giaschi, D. E. (2004). Children with dyslexia: evidence for visual attention deficits in perception of rapid sequences of objects. Vision Res. 44, 2521-2535. doi: 10.1016/j.visres.2004.05.010

Wechsler, D. (1993). Wechsler Intelligence Scale for Children-Revised (WISC-R). Firenze: Giunti O. S. Organizzazioni Speciali.

Wimmer, H. (1993). Characteristics of developmental dyslexia in a regular writing system. Appl. Psycholinguist. 14, 1-33. doi: 10.1017/S0142716400010122

Wright, B. A., Bowen, R. W., and Zecker, S. G. (2000). Nonlinguistic perceptual deficits associated with reading and language disorders. Curr. Opin. Neurobiol. 10, 482-486. doi: 10.1016/S0959-4388(00)00119-7

Yantis, S., and Jonides, J. (1984). Abrupt visual onsets and selective attention: evidence from visual search. J. Exp. Psychol. Hum. Percept. Perform. 10, 601-621. doi: 10.1037/0096-1523.10.5.601

Yeshurun, Y., and Rashal, E. (2010). Precueing attention to the target location diminishes crowding and reduces the critical distance. J. Vis. 10, 1-12. doi: 10.1167/10.10.16

Ziegler, J., Pech-Georgel, C., George, F., and Lorenzi, C. (2009). Speech perception in noise deficits in dyslexia. Dev. Sci. 12, 732-745. doi: 10.1111/j.14677687.2009.00817.x

Ziegler, J. C., Perry, C., Wyatt, A. M., Ladner, D., and Schülte-Korne, G. (2003). Developmental dyslexia in different languages: language-specific or universal? J. Exp. Child Psychol. 86, 169-193. doi: 10.1016/S0022-0965(03)00139-5

Zorzi, M. (2005). "Computational models of reading," in Connectionist Models in Cognitive Psychology, ed G. Houghton (London, UK: Psychology Press), 403-444.

Zorzi, M., Barbiero, C., Facoetti, A., Lonciari, I., Carrozzi, M., Montico, M., et al. (2012). Extra-large letter spacing improves reading in dyslexia. Proc. Natl. Acad. Sci. U.S.A. 109, 11455-11459. doi: 10.1073/pnas.1205566109

Conflict of Interest Statement: The authors declare that the research was conducted in the absence of any commercial or financial relationships that could be construed as a potential conflict of interest.

Received: 30 June 2013; accepted: 02 May 2014; published online: 22 May 2014 Citation: Ruffino M, Gori S, Boccardi D, Molteni M and Facoetti A (2014) Spatial and temporal attention in developmental dyslexia. Front. Hum. Neurosci. 8:331. doi: 10.3389/fnhum.2014.00331

This article was submitted to the journal Frontiers in Human Neuroscience.

Copyright (c) 2014 Ruffino, Gori, Boccardi, Molteni and Facoetti. This is an openaccess article distributed under the terms of the Creative Commons Attribution License (CC BY). The use, distribution or reproduction in other forums is permitted, provided the original author(s) or licensor are credited and that the original publication in this journal is cited, in accordance with accepted academic practice. No use, distribution or reproduction is permitted which does not comply with these terms. 